\title{
A perspectiva territorial no planejamento e gestão do turismo
}

\author{
The territorial perspective on the tourism planning and management
}

\author{
Sarah Marroni Minasi \\ Universidade do Vale do Itajaí -UNIVALI - Itajaí - Santa Catarina - Brasil
}

\begin{abstract}
Resumo: O turismo tem recebido, ao longo dos últimos anos, destaque no contexto econômico do Brasil. Com isso, se intensifica a necessidade de aprofundar o debate em torno desse tema nas suas amplas dimensões. Com vistas a contribuir para as discussões na área do planejamento e gestão pública do turismo, no contexto do desenvolvimento regional, este artigo apresenta como objetivo analisar a compreensão do território no contexto do planejamento e da gestão do turismo. Entende-se a importância do território e a valorização das particularidades na medida em que se procura dar ênfase ao heterogêneo e entender a diversidade regional como potencialidade. A região deve ser entendida como particularidade dinâmica, na qual as ações endógenas presentes no território ganham força. O planejamento do turismo no Brasil vem se pautando em um modelo de gestão pública descentralizada e participativa que promove a integração entre as diversas instâncias de governo. Em virtude disso, o Ministério do Turismo mostra-se empenhado em trabalhar o turismo de forma regionalizada, pelo simples fato de que, na maioria das vezes, a atividade turística não se viabiliza apenas no âmbito de um município. A abordagem teóricometodológica referenciada no materialismo histórico dialético apoiou-se na pesquisa qualitativa, com ênfase na pesquisa documental e bibliográfica, utilizando a análise de conteúdo como procedimento de interpretação de dados. Por fim, compreender o território no contexto do planejamento e gestão do turismo requer buscar respeitar, nas ações de planejamento, os aspectos que particularizam determinado território, ou seja, perceber as particularidades como potencialidades para o desenvolvimento regional.
\end{abstract}

Palavras-chave: Território. Planejamento turístico. Desenvolvimento regional.

Abstract: Tourism has received in the past years emphasis in the economic context of Brazil. Thus, intensifies the need for further discussion in its ample dimensions. To contribute for the discussions on planning and public management of tourism area in the context of regional development, this paper has as main objective to analyze the understanding of the territory in the context of planning and management of tourism. It is understood the importance of the territory and the valuation of the particularities to the extent that it seeks to emphasize the heterogeneous and understand the regional diversity as potentiality. The region should be understood as a dynamic particularity in which the endogenous actions presents in the territory gain strength. The planning of tourism in Brazil has been guided by a model of decentralized and participative public management that promotes the integration among the various instances of government. As a result, the Ministry of Tourism shows itself committed to work the tourism on a regional basis, for the simple fact that, in most cases, tourism is not viable in only one municipality. The theoretical and methodological approach referenced on historical dialectic materialism was supported on qualitative research, with an emphasis on documental and bibliographic research, using content analysis as data interpretation procedure. At last, understand the territory in the context of the planning and public management of tourism requires seek to respect, in the planning actions, the particularities aspects of a specific territory, that is, realized the particularities as potentialities for regional development.

Keywords: Territory. Touristc Planning. Regional Development. 


\section{Introdução}

Em algumas regiões no Brasil o desenvolvimento do turismo, como alternativa econômica, já é realidade. O turismo contribui para o desenvolvimento local e regional, principalmente devido ao fato de valer-se de outras atividades que agregam valor ao seu produto.

Ao tratar do turismo como fator de desenvolvimento regional, pondera-se sobre a importância do planejamento da atividade, o qual busca contemplar uma distribuição espacial mais eficiente e justa dos recursos e das atividades econômicas derivadas. O planejamento do turismo também está intimamente associado à questão da distribuição de renda decorrente da atividade, argumentam Gastal e Moesch (2007).

Devido à sua forma de organização o turismo torna-se consumidor do território, e nessa dinâmica alguns cuidados são requeridos. O território é visto como o espaço e lugar de interação do homem com o ambiente, dando origem a diversas maneiras de se organizar e se relacionar com a natureza, com a cultura e com os recursos de que dispõe. (PNT, 2007). Para isso, busca-se nas formas particulares da interação do homem com o território, elementos que possam fortalecer uma região e assim, com a articulação entre os agentes sociais, econômicos e políticos trabalhar na promoção do desenvolvimento regional.

Este artigo tem como objetivo central contextualizar sobre a compreensão do território no contexto do planejamento e da gestão do turismo.

A abordagem teórico-metodológica referenciada no materialismo histórico dialético apoiou-se na pesquisa qualitativa com ênfase na pesquisa documental e bibliográfica.

O primeiro item deste artigo, "Território, região e regionalização" traz esclarecimentos e diferenciação destes conceitos bem como, suas relações e principais discussões. Na sequência, o item "O planejamento turístico no contexto do desenvolvimento regional" introduz sobre a temática do planejamento turístico, o processo de institucionalização da gestão do turismo no Brasil e ainda a relação o turismo como alternativa para o desenvolvimento regional. Por fim, nas considerações finais evidencia-se que, a valorização das particularidades de cada território pode alavancar o turismo e portanto o desenvolvimento de uma região.

\section{Território, região e regionalização}

A presença constante de uma visão simplificadora nas análises e discussões teóricas transformou os conceitos de espaço, território e região em sinônimos. Tal atitude sabota os avanços teórico-conceituais, formando um emaranhado de significados. Contudo, explicitar devidamente seus significados e discussões é essencial, já que, os termos território e região são centrais para a formulação e desenvolvimento de políticas públicas que tenham como objetivo algum tipo de intervenção no território. Em contraponto as análises que reiteram a referência ao espaço como mera dimensão acessória ou complementar dos problemas ditos substantivos que pretendem tratar. (THEIS e GALVÃO, 2012).

No campo da geografia o conceito de território é considerado como uma estrutura ativa e não restrito a um perímetro delimitado e passivo de intervenções. A noção de território implica, evidentemente, uma dimensão espacial.

O território não é apenas o conjunto de sistemas naturais e de sistemas de coisas superpostas. (SANTOS, 2002). O processo de produção e valorização do território pressupõe o entendimento das relações que dinamizam seu funcionamento, visto que, o território é produto e é condicionado pelas relações sociais. É nesse sentido que de acordo com Theis e Galvão (2012) o território passa a ser definido pelas relações que têm lugar entre atores/agentes/sujeitos e objetos. Segundo Santos (2002, p.10),

o território tem que ser entendido como o território usado, não o território em si. O território usado é o chão mais a identidade. Logo, a identidade representa o sentimento de 
pertencimento, de identificação com o espaço do exercício da vida.

O território caracterizado como o espaço da vida (SANTOS, 2002), revela a ideia de constante transformação, mas sem esquecer os traços do passado, os valores presentes e os impactos de ações futuras. A formação socioespacial indica o modo como o território é usado pela sociedade (SILVEIRA, 2010), logo, os territórios são construídos e desconstruídos socialmente. Assim, Etges (2001) coloca que o território tem que ser visto como algo que está em processo, uma forma-conteúdo, o traço de união entre o passado e o futuro imediato. Ele tem que ser visto como um campo de forças, como um lugar de exercício, de contradições entre o vertical e o horizontal, entre o estado e o mercado, entre o uso econômico e o uso social dos recursos.

É preciso compreender o território como algo socialmente produzido que expressa as contradições do modo de produção capitalista ou as contradições do espaço-mercadoria. (CORIOLANO, 2006).

Raffestin (1993) relaciona a configuração do território a partir do espaço com a figura do ator, ou seja, o território é o resultado das ações conduzidas por um ator sintagmático (ator que realiza um programa) em qualquer nível. Ao se apropriar de um espaço concreta ou abstratamente, o ator territorializa o espaço. Ainda de acordo com o autor, o sentido de agir e a apropriação são expressos ao se concluir que o território é um espaço no qual se projetou um trabalho, seja energia ou informação, e que, por consequência, revela relações de poder. Theis e Galvão (2012, p.62) concluem que "o conceito de território abarca relações de poder que os indivíduos contraem entre si”.

Tais relações de poder tão presentes na definição do território abre espaço para os conflitos. Como aponta Coriolano (2006, p.369) "é o lugar, o espaço das resistências, onde se travam as lutas cotidianas, a exploração das forças de trabalho, o fluxo da mais-valia e a reestruturação produtiva da acumulação capitalista". À medida que novas formações socioespaciais vão se (re)apropriando do território sob uma organização já estabelecida, as dinâmicas de concorrência pelas novas formas de ordenamento territorial desencadeiam e acentuam os conflitos. Cada formação socioespacial impõe a sua própria lógica de ordenação territorial.

O turismo, enquanto atividade produtiva moderna que reproduz a organização desigual e combinada dos territórios capitalistas, na apropriação do território para seu uso, expressa contradições e relações de poder. Como explica Coriolano (2006, p.370).

Os territórios são os meios e produtos das relações de força e de poder produzidas para e pelo turismo, que se estabelecem de forma contraditória e articulada entre o lugar, a nação e o mundo. [...] Para cada modalidade de turismo existe uma demanda espacial.

Compreender a dimensão territorial inerente à atividade turística é compreender a amplitude deste fenômeno que é social, político, econômico e cultural. De acordo com Knafou (1999) é possível relacionar turismo e território em três tipos de situações. Podem existir territórios sem turismo, foi este o caso até a "invenção" do turismo no século XVIII, na Europa Ocidental. E, ainda hoje, apesar da "turistificação" de uma parte do espaço mundial, ainda existem numerosos territórios sem turismo. Pode existir também, um turismo sem território, isto é, resulta da iniciativa de operadores de turismo que colocam um produto no mercado, um produto certamente localizado, tendo alguma relação com o território, mas um produto que não é suficiente para produzir um território apropriado pelos turistas, são lugares de passagem, de território de outros. É este "território que se planeja "por" e "pelo" turismo, o "planejamento do território" é apenas um planejamento do espaço, no qual o turismo é então reduzido a uma atividade econômica, criadora de empregos e lucrativa. Podem, enfim, existir territórios turísticos, isto é, territórios inventados e produzidos pelos turistas, mais ou menos retomados pelos operadores turísticos e pelos planejadores. Isto traz problemas delicados de planejamento, já que não é somente os espaços que se "planeja", mas toda a sociedade. (KNAFOU, 1996, p.71). 
Logo, ao conhecer os processos de formação social do território, conhecer os fluxos materiais e imateriais, é possível compreender a sinergia e a dinâmica de determinada região. É somente com a compreensão do território, com o surgimento de uma territorialidade/identidade que se pode pensar em região e regionalização, se não há entendimento do território, não há regionalização. A região, a partir da perspectiva do território pressupõe ser construída socialmente, e envolver traços de identidade. Esses traços estão presentes na cultura, economia e política. Boisier (1994, p.8) completa que construir socialmente uma região é,

potenciar su capacidad de auto organización, transformando una comunidad inanimada, segmentada por intereses sectoriales, poco perceptiva de su identificación territorial y en definitiva, pasiva, en otra, organizada, cohesionada, consciente de la identidad sociedad-región, capaz de movilizarse tras proyectos colectivos, es decir, capaz de transformarse en sujeto de su propio desarrollo.

Lencioni (1999), afirma que região é um espaço com características físicas e socioculturais, fruto de uma história que teceu relações que enraizaram os homens ao território e que particularizou este espaço. Logo, a autora apresenta uma compreensão dialética do conceito de região.

A ideia de região apresenta-se como particularidade, como mediação entre 0 universal e o singular, como mediação entre o global e o local. Pensando nesse movimento mediador, procuramos demonstrar que a ideia de região, como parte de uma totalidade, tanto quanto o conhecimento geográfico, estão presentes em todas as sociedades. (LENCIONI, 1999, p.196).

A região, de acordo com Silveira (2010), hoje, mais do que nunca, é resultado de interdependências e de uma oposição dialética entre uma ordem global e uma ordem local, com a mediação tantas vezes sem defesa da formação socioespacial.

A região aparece como o ponto de resistência dentro da nova dinâmica da acumulação capitalista, responde às crises globais e ampliadas do capital mundial, submetendo diretamente o estado em favor do mercado (CORIOLANO, 2006), sendo atingida constantemente pela força global mais perversa.

A região não é o lugar da homogeneidade, é resultado da perspectiva de análise do particular. Essa perspectiva pode ser social, cultural, econômica ou ainda uma combinação, composta por diversos conjuntos de atividades e relações sociais entre seus atores. As regiões são construídas, consolidadas, transformadas e decompostas por processos de interação social, política e econômica, desenvolvidos ao longo da história. (BANDEIRA, 2007). Isto implica em entender a região como um conceito dinâmico e não como uma categoria que cristaliza os conteúdos do passado. (SILVEIRA, 2010).

Segundo Limonad (2004, p.55),

a região seria uma resultante da construção histórica desta complexa coerência, construída a partir da dialética articulação (enfrentamento) de distintos processos sociais, que tende a conferir características específicas a um determinado espaço social e a expressar os distintos interesses dos agentes e atores sociais envolvidos.

São os processos de formação e as interações entre os atores sociais que imprimem em cada região suas características próprias, é nesse contexto que surgem as particularidades. Como justifica Coriolano (2006), cada local, região ou país tem sua formação própria, sua cultura, valores e costumes e deste modo a região vai sendo produzido conforme essas relações mais amplas.

É a constante presença do caráter social que atribui à palavra região um sentido afetivo vinculado ao sentimento das pessoas pertencerem a um determinado lugar. (LENCIONI, 1999). O envolvimento nas discussões de interesses priorizados e definidos regionalmente valida 0 sentimento de pertencimento. Num grupo territorialmente constituído a existência de uma identidade regional proporciona a coesão dos atores sociais.

A identidade regional, no sentido da identificação de um conjunto de indivíduos com a "sua" região, é uma forma de identidade social construída historicamente. Surge como resultado de processos políticos, 
sociais e culturais que fazem com que os habitantes de uma determinada área consolidem a percepção de que, apesar das diferenças e divergências que possam ter, também têm afinidades e alguns interesses em comum, que se originam do fato de conviverem em um mesmo território. (BANDEIRA, 2007, p.23).

A identidade regional, no caso de áreas que não correspondem exatamente às esferas municipais e estaduais, isto é, das regiões, é de fundamental importância para a região tornar-se politicamente relevante. A ausência de uma identidade implica, em geral, na incapacidade de articulação em prol dos interesses definidos entre os atores sociais, políticos e econômicos regionais. Nesse caso, como consequência Bandeira (2007, p.23) aponta que "a 'região' tende a não passar de uma segmentação arbitrária do território, sem significado político, constituindo um elemento passivo na prática das políticas públicas".

Essa abordagem leva a crer que 0 ato simplista de agrupar municípios com similaridades superficiais e proximidade geográfica não configura uma regionalização. Uma região não corresponde à uma soma de municípios. (FEGER e ETGES, 2014).

Para Limonad (2004, p.58),

\begin{abstract}
uma regionalização pode fundamentar uma reflexão teórica ou atender às necessidades impostas por uma política setorial, uma prática de planejamento ou por propostas de desenvolvimento regional. As regionalizações possíveis para um mesmo território, podem apresentar variações em função da finalidade a que se propõem a atender.
\end{abstract}

Percebe-se que a regionalização fundamentase na necessidade ou interesse de intervenção ou estudo em determinado território. Tal delimitação depende de critérios e decisões que podem ser políticas, administrativas, sociais, econômicas ou científicas. Não se pode esquecer que além de elementos físicos, o território também é formado por elementos imateriais diversos, conflitantes e dinâmicos. Quando o território não é representado segundo sua diversidade, complexidade e conjunto de interações espaciais resulta na delimitação de áreas que não correspondem ao movimento que ali se processa. Portanto, origina uma regionalização que engessa a realidade ao invés de contribuir para esclarecê-la. (FEGER e ETGES, 2014).

Cabe ressaltar que, os resultados de uma regionalização implicam, em primeiro lugar, atender a demandas da sociedade regional. Como expõe Limonad (2004, p.58-9), "de nada valem investimentos vultuosos em infraestrutura e suportes logísticos, como já assinalava a este respeito Harvey em 1985, seja em áreas articuladas aos fluxos produtivos, seja onde não há dinâmica própria, ou incentivo a investimentos econômicos." Segundo a autora, essa prática tende facilmente a converter regiões em sorvedouros de investimentos que beneficiam grupos específicos de interesses sem tocar nas questões de fundo. Neste contexto, a construção de uma regionalização está centrada no bom desempenho da articulação entre os atores, fundamental para que as regiões se tornem social e politicamente relevantes, como finaliza Bandeira (2007, p.4), "não sendo apenas objeto passivo para ações concebidas e implementadas 'de fora para dentro' e 'de cima para baixo'”.

\section{O planejamento turístico no contexto do desenvolvimento regional}

O turismo do novo século requer solucionar os conflitos de uma maneira construtiva, com uma ampla participação de todos envolvidos (BENI, 2006). Isso se dá por meio de políticas de turismo que busquem maximizar os potenciais que se encontram em nível regional e tratar de maneira diferente destinos e regiões, em detrimento à políticas de caráter setorial e orientadas para o crescimento dos indicadores.

O planejamento do turismo a partir de um modelo de gestão que contemple uma estrutura de participação dos segmentos empresariais, públicos e da sociedade, consolida compromissos permanentes e a busca objetivos comuns. Beni (2006, p.96) aponta que o planejamento do turismo implica conduzir à

gestão compartilhada; participação mútua; definição de programa e produtos que superem os modos tradicionais de fazê-la; elaboração e promoção de produtos que conjuguem sua oferta com sua própria 
rentabilização; identificação de todos os agentes institucionais, sociais e empresariais participantes do processo de desenvolvimento sustentável do turismo na região; elaboração de um plano integrado de turismo; construção de um fundo de recursos para investimentos regionais e para a captação de financiamentos no mercado nacional e internacional.

A valorização do regional ganha força frente às constantes tendências homogeneizantes e aos mercados globalizados. É possível que a região encontre no turismo uma fonte de estímulo às particularidades e diversidades. Coriolano (2006, p.375) explica que,

o movimento reprodutivo do capital mundializado, em sua ânsia de acumulação contínua e ampliada, reforça os conflitos, mas não sem produzir resistências. Como processo hegemônico e homogeneizante, faz surgir a necessidade de defesa dos atores locais para manter as especificidades próprias da história, dos lugares, do local e do regional, valorizando-as para não serem aniquiladas pelos interesses globais.

A regionalização do turismo consiste em promover a construção de um ambiente democrático, coeso, participativo e capaz de envolver poder público, iniciativa privada, terceiro setor e a população territorialmente localizada. O desafio a ser enfrentado atualmente é a regionalização como meio para a elaboração do planejamento.

\subsection{Abordagens sobre planejamento turístico}

O conceito de planejamento encontra-se no rol de conceitos que perpassam por diversos significados de acordo com o interlocutor ou área do conhecimento. A ampla aplicabilidade do termo permite a correlação entre as inúmeras abordagens sobre planejamento. Dessa forma é possível adaptar e conciliar diversos aspectos e assim, "apontar para uma possibilidade distinta daquelas experiências normativas e tecnocráticas dos anos 1950 e 1960". (SILVEIRA e CAMPOS, 2012, p.215).

Lira (1990, p.3) aponta que o planejamento,

no debe confundirse con la elaboración de un documento denominado Plan o Estrategia porque: a) la selección, priorización, análisis de factibilidad y compatibilidad de los objetivos es una tarea permanente que involucra a todos los representantes de las sociedades regionales de un determinado territorio.

É uma atividade que envolve a intenção de estabelecer condições favoráveis para alcançar objetivos propostos. Ele tem por objetivo o aprovisionamento de facilidade e serviços para que uma comunidade atenda seus objetivos e necessidades. (RUSCHMANN, 2001).

A busca do aprovisionamento de necessidades exige o conhecimento da realidade. Para isso o diagnóstico é providencial à construção de um pensamento estratégico sobre aquilo que se pretende em relação à região. De acordo com Lira (1990, p.13), "el 'arte' de elaborar diagnósticos implica la adecuada selección a priori de marcos interpretativos y de utilizar sabiamente la infraestructura y oferta de información existente si es que realmente se quiere avanzar".

O diagnóstico também é elementar ao planejamento do turismo, uma vez que prescinde de ordenação e distribuição de infraestruturas no território, estabelecimento de relações e avaliação das reais potencialidades. No planejamento do turismo, o diagnóstico analisa a infraestrutura turística, os atrativos e a infraestrutura básica, essenciais ao turismo. É com base nesse estudo que serão organizadas ações e políticas de desenvolvimento, tendo sempre em vista objetivos claramente definidos. Ruschmann (2001, p.9) ressalta que "[...] o planejamento dos espaços, dos equipamentos e das atividades turísticas se apresenta como fundamental para evitar danos sobre os meios visitados e manter a atratividade dos recursos para as gerações futuras".

O turismo, como qualquer outra atividade econômica, principalmente no modo de produção capitalista, instala-se onde existem as condições mais favoráveis ao seu desempenho. Nesse caso a condição favorável é a presença de atrativos turísticos, a matéria-prima do turismo. A partir disso, o território do turismo se configura de acordo com as necessidades da atividade. 
Por isso, a principal característica do turismo e também o que o torna tão complexo é a sua relação com o território. O turismo é apontado como atividade que consome elementarmente o território. Cruz (2002) revela que é dessa característica que decorrem suas mais fundamentais especificidades, como a fixidez do seu produto, o atrativo turístico, e a consequente necessidade de deslocamento do consumidor até o produto a ser consumido.

A fixidez do produto do turismo demanda uma lógica de organização do uso do território que lhe é própria. Segundo Cruz (2002, p.12), a nova organização socioespacial estabelecida pelo uso turístico do território dá-se sobre uma organização socioespacial preexistente e seria um engano crer que não há embates decorrentes do encontro dessas diferentes temporalidades. Os nexos antigos assimilam novidades, mas forçam, no limite a coexistência. É a força do local, do espaço contíguo, da co-presença (SILVEIRA, 1997), que se manifesta, que se impõem.

O escopo do planejamento turístico, seus objetivos e ações buscam exprimir claramente a perspectiva de desenvolvimento do turismo que transcende a concepção setorizada e corporativa, para dessa forma, ampliar e articular as diversas dimensões do setor, das organizações, do território e da participação social, em reação aos planos voltados exaustivamente para os aspectos específicos, como o econômico e o físico. (RUSCHMANN, 2001).

Portanto, o modo como se dá a apropriação de uma determinada parte do território pelo turismo está relacionada à política pública de turismo. Na ausência de políticas públicas, o turismo se dá à revelia, ou seja, ao sabor de iniciativas e interesses particulares. (CRUZ, 2002).

O turismo apresenta duas faces, uma voltada a expectativa de lucro e vocação para a concentração de riqueza e renda; por outro lado, a sua face enquanto criadora de oportunidades de ganhos e melhoria na qualidade de vida dos trabalhadores envolvidos e lugares mais pobres (CORIOLANO 2006). É na contradição do que destrói e beneficia que o turismo acontece, isto é, "o turismo se desenvolve à medida que o capitalismo se consolida, vivendo, no entanto, momento de transformação graças às novas concepções que se inserem no mundo do trabalho, como o toyotismo e a flexibilização", afirma Magalhães, (2008, p.96).

Devido ao processo de flexibilização, criam-se "novas formas de circulação de bens, do dinheiro, das ideias, dos comandos, das modas e novas formas de consumo acabam por gerar novas formas de produção" (SILVEIRA, 1997, p.36). Dentro dessa lógica, as trocas são aceleradas, há uma compressão do tempo e do espaço na esfera global, isto é, a dinâmica da globalização também interfere na produção do turismo.

No âmbito do turismo é como se a globalização "funcionasse como uma espécie de lente convexa: quando se olha para um lado, está-se privilegiando o micro; quando se olha para o outro, está-se privilegiando o macro", explica Boisier (1996, p.115). Logo, privilegiar o macro representa as forças homogeneizantes, que massificam os destinos. A perspectiva de privilegiar o micro demonstra uma preocupação em valorizar o que está territorialmente localizado, observando a diversidade como potencialidade para o turismo. Assim, o planejamento do turismo fundamenta-se na contracorrente da globalização, reforçar o lugar da expressão da identidade, sem que isso signifique isolamento. (RODRIGUES, 1997).

É no processo de globalização que o planejamento turístico se faz necessário, uma vez que através do turismo é possível valorizar as particularidades e preservar a identidade da região. Dessa forma, cria-se uma resistência a crescente competitividade perversa imposta pela dinâmica global e a tendência à homogeneização dos destinos.

Diante disso torna-se indispensável o planejamento turístico em âmbito regional, para que deste modo a atividade aconteça de forma ordenada, promovendo a região. É na prática de planejamento e gestão que o poder público tem papel de destaque. Cabe a ele a responsabilidade de priorizar ações que visem à articulação com outros setores econômicos e sociais e igualmente, os envolvidos diretamente com 
o setor do turismo, ações para privilegiar a busca pelo desenvolvimento regional.

O estabelecimento de redes entre as atores de uma região e entre regiões favorece a troca de informações e aprendizado, e se configura também como uma ação de integração. As ações políticas não podem ignorar as informações que os próprios grupos elaboram a partir de seus universos locais de vivência, interação e trabalho. A falta de integração tanto entre os grupos sociais como entre os agentes envolvidos nas outras esferas de gestão dificulta a formulação e execução das ações de planejamento. Portanto, como afirma Lira (1990, p.1-2),

\begin{abstract}
"planificar" no es solo un problema técnico, tampoco una mera tarea del Estado, sino más bien una actividad continua de respaldo a un arduo y lento proceso de diálogo y entendimiento social, protagonizado directamente por los actores reales, públicos y privados, como también por la difusa y creciente gama de las entidades no gubernamentales.
\end{abstract}

Para o turismo se efetivar enquanto alternativa de desenvolvimento regional, não basta o diagnóstico e a elaboração de objetivos. O estabelecimento de relações dentro do setor público, deste com a sociedade, a academia e a iniciativa privada é condição necessária para o desenvolvimento regional do turismo. Contudo, a proximidade geográfica dos agentes envolvidos com o turismo, não é condição suficiente para a cooperação. Esta depende, em primeiro lugar da capacidade de construção de novas territorialidades regionais e a união em busca de um ou mais objetivos comuns.

\subsection{Gestão do turismo no Brasil}

No âmbito da gestão do planejamento do turismo, Boullón (2005) resgata a experiência na América Latina. Como consequência do crescimento que o turismo experimentou durante o último século (século $X X$ ), os países beneficiados por este fenômeno criaram repartições para administrar este novo setor econômico e em seguida tentaram planejá-lo.
Na América Latina, os trabalhos mais sérios nesta área iniciaram-se poucos anos antes dos anos 1970. Durante esse período, a maioria dos países elaboraram seus próprios "Planos Nacionais de Turismo", os quais algumas vezes foram esquecidos e outras vezes atualizados ou substituídos. (BOULLÓN, 2005, p.11-12). Nesse meio tempo, devido à ausência de um número suficiente de técnicos nacionais, a maior parte dos estudos foi encomendada à consultorias estrangeiras ou foi elaborada pelas repartições especializadas de organismos internacionais, como a Organização dos Estados Americanos (OEA), o Banco Interamericano de Desenvolvimento (BID), a Organização Mundial do Turismo (OMT), ou o Banco Mundial, dentro de seus respectivos programas de assistência técnica.

Uma vez recebidos os relatórios finais, surgia um novo problema: colocar em prática. Problema este que em geral não foi resolvido satisfatoriamente devido às estruturas administrativas dos organismos oficiais não estarem preparadas para isto. Assim, com muitos planos e pouco planejamento, o turismo cresceu na América Latina com resultados conhecidos por todos. (BOULLÓN, 2005).

O caso do turismo brasileiro seguiu uma dinâmica semelhante ao resto da América Latina. No país sempre existiram ações que visavam o incentivo ao turismo, contudo, a primeira ação institucional diretamente voltada para a atividade foi a definição da Política Nacional de Turismo, juntamente com a criação do Conselho Nacional de Turismo - CNTur, e a Empresa Brasileira de Turismo - Embratur, no ano de 1996. Nesse período o turismo era visto como uma "indústria" puramente nacional.

Os anos subsequentes foram marcados pela ampliação do debate entre governo, iniciativa privada, academia e sociedade sobre as políticas públicas de turismo, e a percepção deste como fator de desenvolvimento. O primeiro Plano Nacional de Turismo foi resultante desse processo de alargamento das discussões. O plano objetivava diversificar e distribuir geograficamente a infraestrutura que estava altamente concentrada no sul e sudeste. 
Ainda durante a década de 1990, a Embratur passou a seguir as diretrizes da Organização Mundial do Turismo, e lançou o Programa Nacional de Municipalização do Turismo - PNMT, o qual já apontava ações de descentralização das atividades de planejamento do turismo. O PNMT foi o início da trajetória da política nacional de turismo com enfoque territorial. A premissa do programa era dinamizar o desenvolvimento da atividade no âmbito municipal. (MINISTÉRIO DO TURISMO, 2013). O Programa transformou-se em um movimento nacional, o qual conseguiu atingir resultados significativos para seguir em direção ao desenvolvimento com base no territorial.

Somente no ano de 2003 é que foi destinada uma pasta específica para o setor do turismo no Brasil, com orçamento e estruturas próprias. Essa nova estrutura favoreceu a elaboração de um novo Plano Nacional de Turismo - PNT, sob as premissas de um olhar mais especializado no tema. A partir deste momento, o PNT passou a ser revisado a cada quatro anos e atualmente está na terceira revisão.

Nota-se os esforços na busca de constituir no país um modelo de gestão descentralizada e participativa, viabilizando a comunicação e troca de informações entre as esferas da gestão pública, nas diferentes escalas, com a iniciativa privada e terceiro setor. Esse modelo possibilitou ações de planejamento e gestão nos estados, regiões e municípios turísticos do país.

Como forma de aprofundar os resultados obtidos com o PNMT houve a transição para o Programa de Regionalização do Turismo - Roteiros do Brasil (MINISTÉRIO DO TURISMO, 2013). Lançada em abril de 2004, com uma proposta de aproximar a relação entre planejamento, turismo e território, dentro do setor, esta nova estratégia para o desenvolvimento da atividade turística no território foi estruturada com base nas orientações do Plano Nacional do Turismo 2003-2007, o qual teve como objetivo norteador a segmentação, como forma de facilitar o planejamento e a gestão do turismo.

A abordagem do desenvolvimento regional foi uma das principais estratégias para o governo federal alcançar tais metas. Para isso atua buscando a articulação de organismos e instâncias nacionais e regionais, e assim, promover cooperação e interação com os órgãos de administração federal, estadual e municipal.

No sentido de implementar o programa e considerando as diferenças estaduais e regionais, o MTur preparou dois documentos - Diretrizes políticas e Diretrizes operacionais do programa - que contém as principais diretrizes a serem aplicadas pelos agentes do processo nos níveis estadual, municipal e regional. (BENI, 2006).

Segundo as diretrizes operacionais do programa é "um modelo de gestão de política pública descentralizada, coordenada e integrada", cujos princípios "são a flexibilidade, articulação, mobilização, cooperação intersetorial e interinstitucional e sinergia de decisões", compreendendo-se como regionalização "a organização de um espaço geográfico em regiões para fins de planejamento, gestão, promoção e comercialização integrada e compartilhada da atividade turística". (BENI, 2006, p.30).

A partir do Programa de Regionalização do Turismo a esfera regional ganha destaque, propõe-se a compreensão da diversidade como potencial para o desenvolvimento regional. A diversidade regional, enquanto potencial para 0 desenvolvimento, apresenta-se como uma resposta à globalização, uma forma de configurar uma oferta turística com alto poder de atratividade.

Observa-se na intenção do MTur, uma proposta de evidenciar as caraterísticas particulares de cada região, corroborada por Araújo (2000, p.127), quando afirma que "é preciso pensar e agir no Brasil heterogêneo e diversificado, tratar como positivo, como potencialidade (e não como problema) a crescente diferenciação das diversas porções do país". Beni (2006) alerta que a determinação de políticas que não reconhecem as realidades regionais termina por fazer com que haja uma competição perversa entre as diferentes regiões e destinos turísticos. Cruz (2002, p.158), corrobora que "a competitividade entre lugares turísticos, em vez de instigar a valorização à diferença está gerando estandartização e similitude". 


\subsection{O turismo no contexto do desenvolvimento regional}

O desenvolvimento regional, enquanto projeto, provoca a (re)apropriação de um território. Esse processo imprime uma nova organização bem como novos usos, os quais se propõem a alavancar os interesses da sociedade regional. Por meio desse processo viabiliza-se uma nova ordem de desenvolvimento, uma proposta que recusa a racionalidade da acumulação e do consumismo e prima pela qualidade de vida. Para isso, pressupõese buscar atender às necessidades coletivas da base regional e também à melhor alternativa de equilibrar os interesses no processo de desenvolvimento regional.

Para isso é preciso criar formas de representação da vontade da maioria, delineada a partir da legítima participação de todos, e dessa forma permitir que uma nova forma de gestão regional possa atuar. Contudo,

é preciso instalar governos comprometidos, não com a dimensão vertical do processo, expressa no famigerado "leilão do território", cuja manifestação mais conhecida no país é a chamada "guerra fiscal", e sim com a dimensão horizontal do processo, com o olhar voltado para dentro do território, identificando e fomentando as reais potencialidades do mesmo. (ETGES e DEGRANDI, 2013, p.93).

É devido ao objetivo de proporcionar uma alternativa de melhor qualidade de vida que a construção de um projeto político de desenvolvimento regional pressupõe o conhecimento aprofundado da região em questão, visando identificar suas potencialidades, construir instrumentos de coesão social e, principalmente, respeito à diversidade cultural e espacial (ETGES, 2010; ETGES e DEGRANDI, 2013).

É na valorização da diversidade que o turismo adquire destaque dentro da noção de desenvolvimento regional, uma vez que o turista ora parte em busca do familiar, ora busca aquilo que lhe é diferente, exótico, e é nisso que consistem as particularidades, elementos territorialmente localizados que fazem com que cada região seja única.

É dessa forma que se constituirá, no trabalho conjunto do setor público com a iniciativa privada e com a sociedade civil, formas de integração às redes de globalização de forma independente, em vez de serem homogeneizadas por esse processo, ao mesmo tempo em que são reconstruídos os processos de identidade tão necessários aos sujeitos territorialmente localizados (GASTAL e MOESCH, 2007).

Alguns destinos turísticos, na ausência de organização e, frente ao acentuado interesse econômico, desenvolvem-se ignorando as particularidades regionais. Essa prática resulta na perda de autenticidade e distanciamento da identidade cultural. Por outro lado, quando se parte da perspectiva endógena, destacam-se as demandas e particularidades do território. Teles (2006, p.51), adverte que "quando não se planeja o turismo a partir da região, cria-se uma área deslocada de seu contexto". Com base no território, a atividade turística se caracteriza como forma de estimular a diversidade e valorizar a diferença.

A formação de uma região possibilita a participação daqueles municípios que não são dotados de potencial relevante (individualmente) para o turismo. A partir da composição de uma região, é possível que os municípios busquem compartilhar do processo de desenvolvimento do turismo, ressaltando suas particularidades e capacidade produtiva, isto é, promovendo o desenvolvimento regional.

Logo, é necessário perceber a região como um todo, no qual é possível a interação, integração e cooperação entre os municípios. A noção de todo, de união torna-se condição necessária para a gestão bem sucedida que consegue aproximar territórios dispersos e fazer convergir objetivos.

Ao mesmo tempo a cooperação não elimina a competitividade, a qual passa a ser entre regiões e incrementada pelas vantagens comparativas. As vantagens de cada município se fortalecem na composição do todo. Caso contrário, cada município enfrentará a competição de forma isolada e irracional 
culminando no insucesso para ambos. É por meio da aproximação dos territórios e valorização das particularidades que o turismo se mostra uma atividade de grande potencial para promover 0 desenvolvimento regional.

\section{Considerações finais}

Este artigo insere-se no debate sobre o papel do território nas ações de planejamento e gestão do turismo. Entender o território como base para o planejamento do turismo implica em evidenciar os aspectos que particularizam esse território. Para isso, é fundamental a compreensão tanto dos aspectos da formação histórica bem como do contexto atual da região. E a partir disso identificar quais são as reais potencialidades, os conflitos, os entraves procurando encaminhar ações centradas na realidade de cada região e capazes de conciliar os interesses da sociedade.

Habitualmente os termos espaço e território são confundidos na linguagem coloquial, o que contribui para 0 aumento de ambiguidades que cercam esses conceitos. O território só existe a partir da materialidade que the é dada pelo seu uso. Mais do que simples base física, um território traz a marca de gerações que ali viveram e trabalharam.

O turismo não foge à regra das atividades econômicas mais tradicionais e possui sua própria lógica de relação com o território. É uma atividade que depende e é consumidora do território. Consequentemente, influencia sua transformação, requerendo uma crescente racionalidade devido à competitividade entre os produtos turísticos, que se dá, hoje, em escala global. Racionalidade e competitividade aqui expressas sob a perspectiva da criação de vantagem comparativa e não uma competição perversa, dessa forma evidenciando as particularidades presentes em cada território turístico. Para isso é importante que o turismo priorize ações que valorizem as manifestações culturais de forma autêntica, inserindo-as nos destinos turísticos.

O planejamento, a administração, as políticas e a gestão tão solicitados no turismo, não são suficientes para superar os aspectos negativos derivados da atividade. O cerne da questão não está somente na ausência, mas também no conteúdo desses instrumentos. De modo geral, a perspectiva territorial recorrentemente ausente das construções das políticas públicas e planos, impõem uma barreira a possibilidade de planejamento e gestão bem sucedidos. Trazer o território para o centro das políticas públicas e do planejamento turístico aponta a necessidade de um esclarecimento conceitual, no sentido de compreender o significado do termo território na sua essência.

\section{Referências}

ARAÚJO, Tânia Bacelar de. Ensaios sobre o desenvolvimento brasileiro: heranças e urgências. Rio de Janeiro: Revan, 2000.

BANDEIRA, Pedro. Uma Experiência de Institucionalização de Regiões no Brasil: Os COREDEs do Rio Grande do Sul. p.115-162. Anais... Primeiro Colóquio Internacional sobre Desenvolvimento Territorial Sustentável, Florianópolis, $2007 . \quad$ Disponível em:<http://www.lume.ufrgs.br/handle/10183/30 419>. Acesso em 3 de nov. de 2014.

BENI, Mário Carlos.Política e planejamento de turismo no Brasil.São Paulo: Aleph, 2006.

BOISIER, Sérgio. La construcción social del regionalismo latinoamericano (Escenas, discursos y actores). Revista del CLAD Reforma y Democracia, Caracas, n. 2, p.1-19, jul. 1994

Em busca do esquivo desenvolvimento regional: entre a caixa-preta e o projeto político. Planejamento e Políticas Públicas, Brasília, n.13, p.111-143, 1996.

BOULLÓN, Roberto. Os municípios turísticos. Bauru, SP; Educs, 2005.

COOPER, Chris. Et al. Turismo: princípios e práticas. 2 ed. Porto Alegre: Bookman, 2001.

CORIOLANO, Luiza Neide M.T. Turismo: prática social de apropriação e de dominação de territórios. In: LEMOS, Amalia Inés Geraiges; ARROYO, Mônica e SILVEIRA, Maria Laura. (Org.). América Latina: cidade, campo e turismo. Buenos Aires: Clasco, 2006.

CRUZ, Rita de Cássia Ariza da. Política de turismo e território. São Paulo: Contexto, 2000. 
ETGES, Virginia E. A região no contexto da globalização: o caso do Vale do Rio Pardo. In: VOGT, Olgário e SILVEIRA, Rogério. Vale do Rio Pardo: (re)conhecendo a região. Santa Cruz do Sul: Edunisc. 2001.

Desenvolvimento Regional Sustentável: o território como paradigma. Santa Cruz do Sul: REDES, vol 10, n.3, p.47-55, 2005.

ETGES, Virginia E.; DEGRANDI, José Odim. Desenvolvimento regional: a diversidade regional como potencialidade. Revista Brasileira de Desenvolvimento Regional, Blumenau, v.1, n. 1, p. 85-94, outono de 2013.

FEGER, José Elmar; ETGES, Virginia. Regionalização para o planejamento do desenvolvimento turístico: uma discussão sobre critérios para a determinação de áreas com vistas a aplicar a política pública do setor. In: PIMENTEL, Thiago Duarte; EMMENDOERFER, Magnus Luiz; TOMAZZONI, Edegar Luis (Org.). Gestão pública do turismo no Brasil:teorias, metodologias e aplicações. Caxias do Sul: EDUCS, 2014.

GASTAL, Suzana; MOESCH, Marutschka. Turismo, educação e cidadania. São Paulo: Aleph, 2007.

KNAFOU, R. Turismo e território. Para um enfoque científico do turismo. In: RODRIGUES, A. B. et al. (Org.). Turismo e Geografia: reflexões teóricas e enfoques regionais. São Paulo: Hucitec, 1999.

LENCIONI, Sandra. Região e geografia. São Paulo: EDUSP, 1999.

LIMONAD, E. Brasil século XXI, regionalizar para que? Para quem? In: LIMONAD, E. et al. Brasil século XXI - por uma nova regionalização? São Paulo: Max Limonad, 2004.

LIRA, Luis. La confección de estrategias de desarrollo regional.1990.

Disponível em:<http://bibhumartes.ucla.edu.ve/DB/bcucla/ edocs/clases/LDH453/CEDRLuis_Lira.pdf>. Acesso em: 3 de nov. de 2014.

MAGALHÃES, Leandro Henrique. Discussão crítica acerca do turismo numa perspectiva materialista histórica. Caderno Virtual de Turismo, Rio De Janeiro, v. 8, n. 2, p.95-104, 2008.

MINISTÉRIO DO TURISMO. Plano Nacional de Turismo. Brasília, 2013.Disponível em: <http://www.turismo.gov.br/turismo/o_ministerio /publicacoes/cadernos_publicacoes/03planos nacionais.html> Acesso em: 3 de nov. 2014

RAFFESTIN, C. Por uma geografia do poder. São Paulo: Ed. Ática, SP.1993.
RODRIGUES, Adyr B. Turismo local: oportunidades de inserção. In: RODRIGUES, Adyr B. (Org.). Turismo e desenvolvimento local. São Paulo: HUCITEC, 1997.

RUSCHMANN, Doris. Turismo e planejamento sustentável: a proteção do meio ambiente. $8^{\mathbf{a}}$ Ed. Papirus, 2001.

SANTOS, Milton. Território e Dinheiros. In: Território e Territórios. Niterói: Programa de Pós Graduação em Geografia - PPGEO-UFF/AGB, 2002.

SILVEIRA, Maria Laura. América Latina: cidade, campo e turismo. CLACSO, Consejo Latinoamericano de Ciencias Sociales, São Paulo. Dezembro 2010.

Da fetichização dos lugares à produção local do turismo. In: RODRIGUES, Adyr Balastreri. Turismo, modernidade, globalização. São Paulo: HUCITEC, 1997.

SILVEIRA, Rogério Leandro Lima da; CAMPOS, Heleniza Ávila. Processos participativos em experiências recentes de planejamento regional: o caso do Vale do Rio Pardo (RS). REDES, Santa Cruz do Sul, v. 17, n. 1, p. 203 - 216, jan./abr. 2012.

TELES, Reinaldo M. de Sá. A importância do território na prática da planejamento turístico-Reflexões acerca do Brasil. In. RUSCHMANN, Doris Van de Meene; SOLHA, Karina Toledo (orgs.). Planejamento turístico. Barueri: Manole, 2006.

THEIS, Ivo Marcos; GALVÃO, Antônio Carlos. A formulação de políticas públicas e as concepções de espaço, território e região. Revista Brasileira de ESTUDOS URBANOS E REGIONAIS, Rio de Janeiro, v. 14 , n. 2, p. 5568, nov. 2012 